\title{
DIREITO INTERNACIONAL DO MEIO AMBIENTE: PARTICULARIDADES
}

\author{
Paulo de Bessa Antunes ${ }^{1}$ \\ Universidade Federal do Estado do Rio de Janeiro (UNIRIO)
}

\section{RESUMO}

O artigo examina os instrumentos jurídicos disponíveis no âmbito do Direito Internacional para a proteção do meio ambiente, buscando demonstrar que existe, em formação, um Direito Internacional do Meio Ambiente, o qual começa a ser afirmar. Ao longo do artigo são analisadas as principais características capazes de marcar a posição peculiar deste ramo em construção da ordem jurídica internacional. Admite-se que o Direito Internacional do Meio Ambiente é um Direito jovem, que, no entanto, vem aportando importantes novidades na ordem jurídica internacional. $\mathrm{O}$ artigo destaca algumas de tais modificações, e.g., a modificação dos conceitos de responsabilidade e soberania, a ampla utilização de princípios e a transformação gradativa dos sujeitos de Direito Internacional Público. $\mathrm{O}$ artigo ressalta, também, as dificuldades políticas, sociais e econômicas para a efetivação e implementação deste novo ramo do Direito Internacional.

Palavras-chave: ambientalismo; Direito Internacional do Meio Ambiente; globalização; políticas públicas; sustentabilidade.

\section{ENVIRONMENTAL INTERNATIONAL LAW: PARTICULARITIES}

\section{ABSTRACT}

The article examines the legal tools available under international law for the environmental protection, seeking to demonstrate that there is, in formation, an International Environmental Law, which begins to be affirmed. Throughout the article the main characteristics capable of marking the peculiar position of this branch under construction of the international legal framework are analyzed. It is accepted that the International Law of

1 Doutor em Direito pela Universidade do Estado do Rio de Janeiro (UERJ). Mestre em Direito pela Pontifícia Universidade Católica do Rio de Janeiro (PUC-Rio). Professor da UNIRIO. Procurador Regional da República. ORCID: http://orcid.org/0000-0003-0375-0213 / e-mail: paulo.antunes@ unirio.br 
the Environment is a Young Law, which, however, has been contributing with important innovations in the international legal framework. The article highlights some of these changes, for example, the modification of the concepts of responsibility and sovereignty, the wide use of principles and the gradual transformation of the subjects of Public International Law. The article also highlights the political, social and economic difficulties for the implementation and implementation of this new branch of international law.

Keywords: environmentalism; International Environmental Law; globalisation; public policies, sustainability. 


\section{INTRODUÇÃO}

Este artigo tem por objeto a análise de algumas das peculiaridades que nos permitem afirmar que o Direito Internacional do Meio Ambiente (DIMA) é, cada vez mais, reconhecido como um ramo autônomo do Direito Internacional Público (DIP). A proteção do meio ambiente é, atualmente, parte da agenda global e, em tal condição, um dos principais temas discutidos nos diferentes for internacionais, isso permitiu que, no âmbito do DIP, um setor específico começasse a se especializar (REI, 2018). Com efeito, desde 1992, a Organização das Nações Unidas (ONU) realizou diversas conferências internacionais que tiveram como tema central a discussão e deliberação sobre questões ambientais. O DIMAé uma das respostas dadas pela comunidade internacional à a deterioração dos recursos ambientais em escala planetária. É resposta jurídica, originada na compreensão comum dos sujeitos de Direito Internacional no sentido de que somente uma ação uniforme e articulada entre os diversos atores internacionais é capaz de solucionar problemas que ultrapassam a fronteira de um único estado. O DIMA surgiu no século XX, assim como a questão ambiental. É fato que, no passado, existiram alguns acordos internacionais sobre problemas comuns que afetavam os seus recursos naturais. Entretanto, foi somente no século passado que a preocupação se tornou mais eloquente e visível no cenário internacional. Todavia deve ser observado que o interesse com a proteção do meio ambiente surge, inicialmente, no âmbito interno de cada país e, daí, se propaga para a arena internacional. Uma condição essencial para que o DIMA se desenvolva é a existência de instituições internacionais estáveis que expressem, no mínimo, o desejo de cooperação entre os Estados, pois, não é concebível o tratamento de problemas multilaterais, sem instituições que os articulem, de forma pacífica e cooperativa. O tema meio ambiente e o direito que sobre ele incide têm vocação universal (MORAND-DEVILLER, 2010) e como tal, precisam ser abordados de forma que envolva a comunidade internacional e os diversos mecanismos por ela criados.

O DIMA pode ser definido como o conjunto de regras (cogentes ou não), princípios e práticas internacionais que criam obrigações e direitos relativos à proteção do meio ambiente, da natureza e dos recursos naturais no âmbito da comunidade internacional. Nele estão incluídas as matérias que, simultaneamente, são de interesse de múltiplos Estados, tais como as poluições transfronteiras, os recursos do mar, as mudanças climáticas globais e a proteção da diversidade biológica, bem como matérias de 
interesse regional, e. g., a proteção de um determinado rio internacional ou de florestas que se espalham por mais de um país.

Geraldo Eulálio do Nascimento e Silva (2002) sustenta que a Assembleia Geral das Nações Unidas (AGNU), ao convocar a Conferência do Rio de Janeiro utilizou a expressão "Direito Ambiental Internacional", resolvendo o problema relativo à existência de um novo ramo do DIP, quanto à designação, a prática tem preferido utilizar Direito Internacional do Meio Ambiente, adotada neste artigo.

O DIMA é composto pelos tratados, convenções e declarações internacionais relativos à proteção da natureza, sendo muito difícil identificar coerência entre as suas diferentes normas. A harmonização entre todo o conjunto é tarefa dificílima, senão impossível. Dessa forma, é melhor utilizar a noção de setores próprios no interior do DIMA, ou seja, que se busque a harmonização entre conjuntos específicos de tratados e convenções internacionais. Igualmente, não se deve desconsiderar as profundas relações entre o DIMA e o Direito Internacional dos Direitos Humanos e, também, com o Direito Internacional Econômico, haja vista a grande interpenetração entre eles. Logo, o DIMA é abrangente e não pode ser entendido fora dos contextos econômicos e sociais. A Declaração de Estocolmo, proclamada em 1972, é uma demonstração eloquente do que se argumenta. Na proclamação1 a Conferência afirma que o meio ambiente humano possui dois aspectos, a saber: (1) o natural; e o (2) artificial (ONU, 1972). Ambos são essenciais para que o Ser Humano desfrute de bem-estar e dos direitos humanos fundamentais e até mesmo da própria vida. Assim, protegê-lo e melhorá-lo é uma questão fundamental que afeta o desenvolvimento econômico de todo o mundo, sendo desejo dos povos e obrigação dos governos.

Dentre as características mais marcantes do DIMA podem ser apontadas: (1) a sua juventude (MALJEAN-DUBOIS, 2008); (2) a sua setorização; (3) o seu caráter prospectivo; (4) a modificação do conceito de soberania nacional; e (5) a transformação de seus elementos constitutivos, tais como sistema de fontes e os seus sujeitos. Estes são os pontos que o artigo pretende examinar de forma crítica.

\section{A JUVENTUDE DO DIREITO INTERNACIONAL DO MEIO AMBIENTE}

Este tópico examinará a juventude do DIMA, isto é o seu caráter de novidade no universo jurídico em comparação com o DIP que é direito 
cujas origens se perdem nas brumas do tempo. Francisco Rezek (2002) afirma que o primeiro tratado bilateral comprovadamente existente foi o firmado entre Hatusil III, rei Hitita, e Ramsés II, faraó egípcio. Acredita-se que a paz entre as nações tenha sido firmada entre 1280 e 1272 a.C. Surgido na época das poluições globais, o DIMA, com a inquietação própria dos jovens necessita romper as barreiras de um modelo jurídico milenar para encontrar a sua afirmação plena. Como se verá, tal rompimento será feito pela adoção de mecanismos próprios que serão tratados nos tópicos subsequentes.

\subsection{Importância do ambientalismo para a formação do DIMA}

O DIMA é fruto do ambientalismo que é movimento social e político, composto por diferentes e, até mesmo, antagônicos pensamentos sobre a natureza, a sua proteção e o seu papel no mundo moderno. Conforme a arguta visão de David Pepper (2000), ele nos traz a sensação de que provém de todos os lados, da esquerda, da direita, do centro, misturando-se com conceitos oriundos da ecologia. Nele estão albergados o biocentrismo e o antropocentrismo, sendo, portanto, difícil definir em concreto a política verde. Esta "mélange" (PEPPER, 2000), todavia, é um fato que possui grande impacto na produção do DIMA. O ambientalismo se baseia em um discurso (HANNIGAN, 2014) que também é um grande contribuinte para a formação do DIMA. Tal discurso é formado por um conjunto de afirmações, muitas delas com base em argumentos científicos, sobre como a natureza deveria ser, caso fossem evitadas determinadas práticas que a colocam em risco, sendo consequência da urbanização e do crescimento industrial acelerados no pós-guerra da Europa e dos Estados Unidos, chegando a se falar em "revolução ambientalista" (McCORMICK, 1992). Em geral, o discurso ambientalista tende ao alarmismo e ao espetacular, dramatizando os problemas reais.

O discurso ambientalista moderno parte de duas obras seminais: Primavera silenciosa, de Rachel Carson (2010) e no relatório do Clube de Roma, Os limites do crescimento (MEADOWS et al., 1977). O capítulo inaugural de Silent Spring tem o sintomático título de Uma fábula para amanhã no qual, à semelhança dos contos infantis, afirma-se que havia uma cidade no coração dos Estados Unidos semelhante ao jardim do éden, demonstrando desconforto com o mundo moderno e as suas mazelas. Silent Spring é, certamente, a obra mais influente no pensamento ecológico 
até os dias presentes. Nela constam as preocupações com a guerra nuclear e com a poluição do ambiente por produtos químicos, vinculando-os com armas de guerra e com a sua utilização como veneno para suicidas etc. Não há nenhuma questão presente na agenda ambiental atual que não tenha estado presente em Silent Spring. O manifesto trata de questões que vão desde a ameaça do holocausto atômico até a contaminação do leite materno por produtos químicos. Ela fala das pequenas comunidades e da participação popular e dos riscos trazidos pela ciência moderna. Alarmista, em uma época na qual a preocupação com a guerra fria e as explosões termonucleares eram reais; radical no banimento dos organoclorados, podemos dizer que a Convenção de Estocolmo sobre Poluentes Orgânicos Persistentes é um subproduto de Silent Spring. A influência de R. Carson também está presente no discurso do Ex-Secretário-Geral da ONU, U Thant ao afirmar que não desejava parecer "excessivamente dramático", mas que a sua condição de Secretário-Geral permitia-lhe concluir que os integrantes das Nações Unidas dispunham "talvez de dez anos" para controlar a corrida armamentista, melhorar o ambiente humano e controlar a explosão demográfica. Para enfrentar os problemas ele propunha a criação urgente de um órgão internacional, sob pena de que a humanidade perdesse o controle da questão (MEADOWS et al., 1977).

\subsection{Um Direito na encruzilhada}

O tratamento jurídico do meio ambiente tem gerado perplexidade na comunidade jurídica, pois dadas as suas características peculiares, não é possível a sua inserção nos usuais escaninhos do Direito. Raphaël Romi (2010) afirma que o Direito Ambiental se encontra na encruzilhada entre o Direito Público e o Privado, entre o Direito Interno e o Internacional. Isto se deve ao fato de que o próprio ambiente não respeita fronteiras, muito menos os danos que sofre. Dessa forma, a proteção ambiental não se limita a um único caminho legal, nem a um único ramo do Direito. Todos os recursos jurídicos são válidos para a defesa ambiental. Assim, a sua proteção, do ponto de vista jurídico, não se faz pela construção de uma torre paralela aos vários ramos do Direito, mas antes pela perfuração transversal do tema ambiente em todo e qualquer ramo do Direito, ainda que se reconheça e admita a existência de um setor jurídico especializado.

Em tal contexto, o DIMA desempenha papel fundamental, pois grande parte dos problemas ambientais enfrentados pelos países são globais ou 
regionais, o que demanda solução jurídica que também o seja. É relevante frisar que o DIMA, em relação aos direitos internos, exerce o papel de locomotiva (MALJEAN-DUBOIS, 2008), puxando os ordenamentos nacionais em direção a um padrão mais elevado de proteção.

As encruzilhadas do Direito Ambiental não se limitam aos aspectos internos da ordem jurídica, seja ela nacional ou internacional. Há que se considerar os aspectos externos (metajurídicos em visão positivista) como essenciais na construção e na aplicação da proteção jurídica do ambiente. O formulador da norma e o seu aplicador, não podem deixar de considerar os aspectos políticos, econômicos, científicos e sociais envolvidos em uma situação concreta. Logo, o Direito age como um catalizador de diversos conhecimentos e momentos que se materializarão em uma norma jurídica que é pensada para regular uma situação presente, e principalmente para moldar o futuro. Esses caminhos cruzados estão à base das dificuldades concretas para a implementação do Direito Ambiental, em qualquer âmbito que seja.

\section{A SETORIALIZAÇÃO DO DIMA}

O meio ambiente é entendido como uma totalidade que engloba todos os chamados recursos naturais do planeta, assim como as obras da cultura humanas. Dada a amplitude do conceito, torna-se uma impossibilidade tratá-lo de forma única. A Corte Internacional de Justiça (CIJ) na célebre decisão do caso do Projeto Gabiciknovo-Nagyamaros (Hungria v. Eslováquia) estabeleceu que o meio ambiente não é uma abstração, mas o espaço no qual vivem os seres humanos e do qual dependem as suas qualidades de vida e saúde, inclusive quanto às gerações futuras. Entretanto, dos pontos de vista práticos e normativos, há dificuldade real de se chegar a um acordo multilateral que trate de "meio ambiente". Desta forma, os Estados têm, nas suas práticas concretas, firmado acordos internacionais setoriais, cujos principais dizem respeito à (1) proteção da diversidade biológica, incluindo a proteção de flora, fauna e recursos genéticos; à (2) proteção dos recursos hídricos marítimos e fluviais; à (3) proteção contra a poluição transfronteira, incluindo produtos tóxicos e a poluição química; e à (4) proteção da atmosfera, inclusive no que tange às mudanças climáticas. Como se verá no tópico seguinte, o DIMA tem se utilizado amplamente das chamadas convenções-quadro que são acordos abertos e gerais que demandam a adoção de medidas posteriores para a sua efetiva concretização. 


\subsection{Tratados e convenções ambientais}

Os tratados, conforme definido na Convenção de Viena sobre o Direito dos Tratados, artigo 1 (a), são acordos internacionais formais e escritos, celebrados entre Estados e submetidos às regras do Direito Internacional, podem ser celebrados em documento único ou em vários documentos conexos, independentemente do nomem iuris. Segundo a observação de Stéphane Doumbé-Billé et al. (2013), os tratados quantitativamente são as normas mais importantes do DIMA. Para os autores, os primeiros tratados ambientais remontam ao Século XIX, ainda que não fossem voltados para a proteção ambiental em si mesma, mas a de outros bens jurídicos e econômicos, como é o caso da Convenção de Paris de 1902 sobre a proteção dos pássaros úteis para a agricultura (VARELLA, 2009). Em geral, segundo o Ministério das Relações Exteriores brasileiro, o termo tratado é utilizado para os acordos aos quais se pretende atribuir importância política (BRASIL, 2020). O DIMA utiliza muito as convenções que são atos multilaterais sobre temas de interesse geral, resultado de conferências, frequentemente usados em questões comerciais, industriais, de direitos humanos e meio ambiente.

Em matéria ambiental, as convenções-quadro, tais como a Convenção sobre Diversidade Biológica, v.g., são documentos de grande relevância, dada a sua condição de serem acordos amplos, permitindo a acomodação das diferentes visões das Partes, de modo a ter vida longa (SANDS; PEEL, 2017). Normalmente, dada a complexidade do tema, os Estados estabelecem Protocolos que são documentos interpretativos dos tratados ou convenções. No caso da Convenção das Nações Unidas sobre Mudanças do Clima, foi firmado o Protocolo de Kyoto (BRASIL, 2002), que, muito embora tenha entrado em vigor em 16 de fevereiro de 2005, fracassou devido a dificuldades políticas. Ele foi substituído pelo Acordo de Paris que se viabilizou pelo fato de expressar compromissos voluntários assumidos pelas Partes para a redução da emissão de gases de efeito estufa (GEE). Nesta altura é relevante anotar que o Protocolo de Montreal sobre Substâncias que destroem a Camada de Ozônio, originado da Convenção de Viena para a Proteção da Camada de Ozônio, é amplamente exitoso, sendo "o único acordo ambiental multilateral cuja adoção é universal: 197 estados assumiram o compromisso de proteger a camada de ozônio" (BRASIL, 2019).

Lavielle, Delzangles e Le Bris (2018) dividem os tratados ambientais em dois grandes grupos: a (1) luta contra a poluição; e (2) a defesa dos 
recursos naturais. O primeiro grupo é formado por acordos protetores de meios específicos, e.g., a água, o ar, o solo etc. Já o segundo grupo engloba os chamados domínios de proteção, e.g., a diversidade biológica, ou espécies da flora e da fauna. A divisão é meramente didática, dada a interdependência dos temas. Se um acordo protege um dado ecossistema contra a poluição química, certamente protegerá a diversidade biológica nele contida.

Os tratados e convenções podem ter uma vocação (1) universal, ou seja, buscam congregar todos os estados em torno de um único tema; ou (2) regional, abrangendo apenas os estados geograficamente localizados em uma região. Todavia, alguns acordos regionais também aceitam a adesão de Estados fora da região original, como é o caso da Convenção de Aarhus, artigo 19 (3), que admite a adesão de Estados com status consultivo junto à Comissão Econômica da Europa. Quanto aos efeitos sobre o meio ambiente, Lavielle, Delzangles e Le Bris (2018) identificam quatro tipos de convenções: (1) as inteiramente dedicadas ao meio ambiente; (2) àquelas dedicadas à uma região específica com disposições ambientais, e.g., o Tratado da Antártida; (3) tratados que não tenham natureza ambiental, como os de desarmamento que, indiretamente, protegem o meio ambiente; e (4) tratados comerciais que, sem as devidas cláusulas ambientais, podem gerar efeitos nocivos sobre o meio ambiente.

A produção de tratados e convenções em tema ambiental, nos últimos 40 anos, é impressionante. O Registro de Tratados Internacionais e outros Acordos no campo do Meio Ambiente, edição de 2005 indica a existência de 50 principais tratados internacionais sobre meio ambiente entre os anos 1920 e 1970; já de 1971 a 2005, o número total de tratados constantes da publicação chega a 272, dividindo-se em diversas matérias (UNITED NATIONS, 2005). Não se sabe exatamente qual o número total de acordos existentes em nível regional e sub-regional, entretanto, estima-se que possam ultrapassar 2000 (SANDS; PEEL,2017). O grande número de acordos internacionais, se por um lado demonstra uma crescente preocupação global com o assunto, por outro é um elemento complicador, pois torna o DIMA extremamente fragmentado e de dificílima aplicação e, até mesmo, meramente simbólico, caso não haja implementação concreta.

Como regra geral, a formação dos tratados e convenções ambientais, não é diferente do que ocorre em outros setores do DIP. Contudo, há algumas peculiaridades nos acordos ambientais que merecem destaque. Em primeiro lugar, está a existência de uma agenda comum entre dois ou mais Estados ou, ainda, organização internacional e que tais atores 
estejam dispostos a discuti-la, com vistas a alcançar algum nível de entendimento compartilhado. Faz-se necessário, igualmente, que os Estados tenham atingido algum nível de consenso interno em relação às políticas a serem adotadas, pois do contrário, é praticamente impossível uma atuação coerente em nível internacional, sobretudo em função do fato de que, nos dias atuais, a negociação e elaboração de tratados e convenções internacionais não é mais feita sob o exclusivo patrocínio dos ministérios de relações exteriores ou dos negócios estrangeiros, havendo a crescente intervenção de agências governamentais específicas em matéria ambiental na equipe negociadora. Além dos atores estatais que, sem dúvida, são principais agentes nas negociações internacionais, é relevante ressaltar que no campo ambiental, é crescente a intervenção da agentes não estatais, tais como Organizações Não Governamentais (ONG), instituições financeiras, sociedades científicas, corporações transnacionais, povos indígenas e populações tradicionais e, até mesmo indivíduos, ainda que, por fim, caiba aos Estados e as Organizações Internacionais a assinatura dos acordos. Todavia, do ponto de vista da realidade concreta, não se pode deixar de reconhecer que, não com pouca frequência, as corporações internacionais e ONGs possuem mais poder real do que os chamados países menos desenvolvidos (UNITTED NATIONS, 2019b). As disparidades econômicas entre os Estados e as diferentes visões sobre o próprio conceito de meio ambiente e de desenvolvimento, inclusive no que tange à concepção de desenvolvimento sustentável, tem servido de freio para a implementação de diversos acordos, sobretudo pela vocalização dos agentes não estatais, muitas vezes, em função da falta de equidade entre os termos propostos (CORNWALL; EADE, 2010).

As convenções-quadro, demandam a criação de novas estruturas para a sua implementação e fiscalização, acarretando custos e criação de burocracias internacionais. Tais estruturas têm formas variadas que, em geral são: os (1) secretariados; as (2) conferências das partes como estruturas físicas. Em termos documentais acordados: os (1) anexos; e (2) outros instrumentos jurídicos.

A convenção-quadro define os instrumentos que serão constituídos, quando da sua entrada em vigor. Exemplificativamente, a Convenção-Quadro das Nações Unidas sobre Mudanças Climáticas, em seu artigo $2^{\circ}$ estabelece que a Conferência das Partes poderá adotar instrumentos jurídicos com a finalidade de atingir os objetivos da própria Convenção. Por sua vez, os artigos 7, 8, 9, 10 e 11 estabelecem uma (1) Conferência das Partes; (2) 
um Secretariado; (3) um Órgão Subsidiário de Assessoramento Científico e Tecnológico; (4) Órgão Subsidiário de Implementação; e (5) um mecanismo financeiro vinculado à Convenção. A Conferência das Partes, criada pela própria convenção [artigo 7 (2)], é o órgão máximo da Convenção competindo-lhe acompanhar a sua implementação e a de quaisquer outros instrumentos jurídicos que a Conferência das Partes adote, bem como tomar decisões, conforme o seu mandato, para a efetiva implementação da convenção. É certo que as convenções - quadro deram margem à criação de estruturas complexas e caras que têm sido objeto de muitas críticas por parte, sobretudo, de ONGs que questionam os gastos e a sua pouca efetividade, haja vista que a própria ONU admite que a qualidade ambiental global vem se deteriorando (UNITED NATIONS, 2019a).

\section{NATUREZA FINALÍSTICA E PROSPECTIVA DO DIMA}

O DIMA, como se verá no presente tópico, é Direito finalístico, voltado para a consecução de objetivos e modelagem de um futuro a ser construído segundo o modelo da sustentabilidade ambiental, social e econômica. Ele não acomoda situações passadas, antes busca organizar o porvir. Estes dois elementos, em conjugação, denotam particularidades inovadoras e, ao mesmo tempo, conservadoras. Inovadoras, na medida em que os acordos internacionais objetivam, como já foi visto, a melhoria das condições ambientais atuais e a modificação de padrões de produção e consumo; conservadoras, na medida em que visam à manutenção dos recursos ambientais ora existentes para as gerações do amanhã.

\subsection{Natureza finalística}

Para Alexandre Kiss (1989), assim como para Dupuy e Viñales (2015), o objetivo do DIMA é a proteção da biosfera contra as grandes deteriorações e desequilíbrios que perturbem o seu funcionamento normal, o que os autores reconhece ser tarefa complexa. Todavia, ao argumentar sobre a natureza finalística do DIMA, Kiss relembra que a AGNU (Resolução 2749 (XXV) de 17 de dezembro de 1970), declarara solenemente serem os fundos marinhos e oceânicos, bem como os seus subsolos, ainda que além dos limites de jurisdição nacional, e os recursos neles existentes, "patrimônio comum da humanidade", devendo a sua exploração e aproveitamento serem feitos em benefício da humanidade, independentemente da situação 
geográfica dos Estados. A proclamação foi incorporada à Convenção das Nações Unidas sobre o Direito do Mar, artigo 137 (2).

É fato que, atualmente, o termo meio ambiente se banalizou (RÈMOND-GOUILLOUD, 1989) sendo utilizado de forma aleatória e quotidiana pela imprensa, políticos, ambientalistas e um sem número de pessoas e entidades, muitas vezes sem uma concordância clara sobre o seu significado. Portanto, a definição do objeto do DIMA vai depender do que se entenda por meio ambiente. No Direito interno brasileiro, por exemplo, há duas definições de meio ambiente, a (1) constitucional no artigo 225 da Constituição da República que o define como um bem de uso comum do povo, essencial à sadia qualidade de vida; e (2) a legal que o define como o conjunto de condições, leis, influências e interações de ordem física, química e biológica, que permite, abriga e rege a vida em todas as suas formas. A definição constitucional tem caráter antropocêntrico, enquanto a legal ressalta os aspectos ecológicos.

Neste ponto, não se pode evitar a dicotomia entre antropocentrismo e biocentrismo. $\mathrm{O}$ antropocentrismo tem a humanidade como o centro de importância sobre todos os fenômenos, assumindo que os seres humanos são completamente separados e independentes da natureza física (EBLEN; EBLEN, 1994); por sua vez o biocentrismo admite que toda forma de vida é dotada de igual valor. O DIMA tem oscilado entre posições antropocentrista e biocentrista, como decorre de alguns de seus documentos relevantes. A Convenção das Nações Unidas para a Proteção do Patrimônio Mundial, Cultural e Natural firmada em Paris (16 de novembro de 1972) afirma concomitantemente, ambas as concepções, conforme o disposto em seu artigo $2^{\circ}$ que protege tanto obras produzidas pelo gênio humano, como belezas naturais, cênicas, formações físicas e biológicas que tenham valor universal excepcional, seja dos pontos de vista estético, científico ou da conservação.

A Declaração de Estocolmo, em seu Princípio 2, é antropocentrista e utilitarista, ao dizer que os recursos naturais, em especial, as amostras representativas dos ecossistemas naturais devem ser preservadas em benefício das gerações presentes e futuras. Já a Carta da Terra, em seu artigo 1, adere ao biocentrismo, ao dizer que os seres vivos são interligados, ostentando valor independentemente de sua utilidade para os Humanos.

A Carta Mundial da Natureza (Resolução 37/7 de 28 de outubro de 1982 da AGNU) afirmou a importância da proteção dos ecossistemas e da natureza para a sobrevivência da humanidade, proclamando que: a (1) 
Humanidade é parte da natureza, sendo a vida dependente do funcionamento ininterrupto dos sistemas naturais, os quais garantem os suprimentos de energia e de nutrientes; a (2) civilização precisa da natureza, a partir da qual a cultura humana e todas as conquistas artísticas e científicas foram construídas, portanto, a vida harmônica com a natureza oferece ao Homem as oportunidades para desenvolver toda a sua criatividade, inclusive para o descanso e o lazer. Os seus cinco princípios gerais são: (1) a natureza deve ser respeitada e os seus processos essenciais não devem ser prejudicados; (2) a viabilidade genética da Terra não deve ser comprometida; o nível populacional diversas formas de vidas deve ser, no mínimo, o suficiente para as suas sobrevivências e, para este fim, os habitats necessários devem ser protegidos; (3) todas as áreas da terra, terrestres e marítimas, deverão se submeter aos princípios de conservação e que proteção especial deverá ser atribuída para áreas únicas, para as amostras representativas de todos os diferentes tipos de ecossistemas e para os habitats de espécies raras ou ameaçadas; (4) os ecossistemas e organismos, assim como os recursos terrestres, marinhos e atmosféricos, utilizados pelo Homem, devem ser manejados de forma a atingir e manter uma produtividade sustentável ótima, mas não de forma a ameaçar a integridade de outros ecossistemas ou espécies com os quais coexistem; e (5) a natureza deve ser protegida contra a degradação causada por guerras ou outras atividades hostis.

Há que se mencionar também a Carta da Terra que é fruto de inciativa da Comissão Mundial das Nações Unidas sobre Meio Ambiente e Desenvolvimento (Comissão Brundtland) que, em 1987 lançou o conhecido relatório Nosso Futuro Comum, do qual consta o conceito de desenvolvimento sustentável. Em 1994, iniciativas adotadas por Maurice Strong e Mikhail Gorbachev, com o apoio do governo holandês, lançaram a ideia para o desenvolvimento da Carta da Terra. Em 1997 foi formada a Comissão da Carta da Terra. Somente no ano 2000, chegou-se a um consenso, no âmbito da UNESCO, sobre a sua redação. A Carta da Terra, muito embora expresse uma visão internacional sobre as questões ambientais, é um direito in fiere, sem qualquer força normativa.

\subsection{Natureza prospectiva}

O DIMA é um Direito que não se limita às situações presentes. É mais do que um Direito meramente reativo, sua pretensão é mais ampla: busca dispor para o futuro. Isto não é, todavia, tarefa fácil. A vinculação do 
DIMA ao futuro se faz em bases antropocêntricas, pois seu discurso é basicamente voltado para as "gerações futuras", o que tem sido entendido como gerações humanas. Aliás, não poucos autores (DUPUY; VIÑALES, 2015; CALVO, 2005) admitem a existência do princípio da equidade intergeracional que, em síntese, é a utilização dos recursos ambientais pelas gerações presentes, sem exauri-los, permitindo a sua utilização futura. A Declaração de Estocolmo (Princípio 1) afirma o Homem tem a solene obrigação de proteger e melhorar o meio ambiente para as atuais e para as próximas gerações. A Declaração do Rio (Princípio 3) é mais clara ao cuidar da equidade intergeracional, dispondo que o direito ao desenvolvimento deve ser exercido de forma a atender equitativamente às necessidades do desenvolvimento, do ambiente e das gerações presentes e futuras. Releva anotar que não é apenas no Soft Law que a preocupação com as gerações do amanhã é encontrável, e.g., a Convenção sobre Diversidade Biológica (CDB) também é volta da para o futuro.

\section{ESTADOS NACIONAIS E SOBERANIA}

O multilateralismo das questões ambientais faz com que, não raras vezes, diversos Estados se queixem de perda de sua soberania em função de acordos ambientais, bem como se sintam prejudicados em razão da existência crescente de organismos internacionais dedicados ao tema. Este comportamento é bastante recorrente entre os países emergentes e os menos desenvolvidos que, seguidamente, mostram desconfiança em relação a um novo padrão de governança internacional. Como se espera demonstrar neste tópico, o multilateralismo é uma característica do DIMA e, certamente, não pode ser confundido com perda de soberania, mas é, isto sim, uma nova forma de sua expressão. Também merece destaque o fato de que as peculiaridades do tema ambiental acarretam o ingresso de novos atores no cenário internacional, tais como associações civis das mais diversas naturezas, povos indígenas e tradicionais e até mesmo indivíduos.

\subsection{Papel dos Estados nacionais}

Os Estados nacionais são dotados de soberania, isto é, exercem jurisdição o que implica no exercício de poder político e jurídico sobre os seus territórios e domínio permanente sobre os seus recursos naturais (UNITED NATIONS, 1962). A Resolução da AGNU foi adotada no auge do processo 
de descolonização quando especialmente as jovens nações africanas buscavam assegurar que os seus recursos naturais permanecessem sob os seus controles e, em tese, pudessem reverter em favor de suas populações, afirmando as suas independências em face das antigas potências coloniais. Tal concepção tem sido reafirmada no DIMA, conforme demonstram o Princípio 21 da Declaração de Estocolmo, o Princípio 2 da Declaração do Rio e o artigo 3 da CDB, dentre outros documentos. Contudo, em matéria ambiental, o tradicional conceito de soberania tem sofrido mitigações que merecem menção.

Os Estados, independentemente de suas dimensões territoriais, de suas capacidades econômicas e de sua população são juridicamente iguais perante a comunidade internacional, conforme disposto no artigo 2 (1) da Carta das Nações Unidas. A peculiaridade do conceito de soberania no DIMA encontra suas origens no ano de 1935, quando uma fundição canadense situada próxima à fronteira dos Estados Unidos (Estado de Washington) emitia gases (dióxido de enxofre), causando danos a plantações e florestas além-fronteiras. Os Estados Unidos acionaram o Canadá perante a Corte Arbitral que julgou procedente a reclamação, condenando o Canadá ao pagamento de compensações e estabelecendo o princípio de que nenhum Estado tem o direito de usar ou permitir que se use o seu território de forma a causar danos a outros países ou a propriedades e/ou pessoas de terceiros estados. Firmou-se assim, o conceito de responsabilidade internacional dos Estados.

A imposição de responsabilidade aos Estados é tema árduo, haja vista a inexistência de um poder global capaz de executá-la, ao menos em relação às grandes potências. Acresce as evidentes diferenças econômicas, sociais e políticas existentes na comunidade internacional. Esta é uma das razões pelas quais há enorme pressão e mesmo desconfiança dos Estados em vias de desenvolvimento e dos Países Menos Desenvolvidos em relação às responsabilidades ambientais. A discussão sobre as mudanças climáticas globais é um excelente exemplo do que se fala, pois os países emergentes e recentemente industrializados afirmam que a maior parte dos GEE atualmente existentes na atmosfera tem sua origem nos países desenvolvidos, estes por sua vez sustentam que, nos dias atuais, os maiores emissores são os emergentes. A propósito, não se deve desconsiderar a terceirização das emissões, dada a massiva transferência das atividades emissoras dos países desenvolvidos para os emergentes.

Esse contexto serve de base para o conceito de responsabilidades 
comuns, porém diferenciadas que está presente, e. g., no Princípio 7 da Declaração do Rio, dentre outros acordos internacionais, tais como o Acordo de Paris em seu artigo $2^{\circ}(2)$.

\subsection{Responsabilidades comuns, porém diferenciadas}

A comunidade internacional reconhece que todos os seus membros têm o dever de proteger o meio ambiente e de trabalhar para a sua melhoria. Há, portanto, uma responsabilidade comum a todos. As diferenças de níveis de consumo, renda, utilização de recursos ambientais etc., impedem concretamente que todos os Estados sejam igualmente responsáveis pela recuperação dos danos ao meio ambiente, ou mesmo pela sua mitigação. É indisputável que os maiores consumidores de recursos ambientais são os países desenvolvidos, cabendo-lhe a maior responsabilidade com relação às medidas de recuperação e prevenção e/ou mitigação que se façam necessárias.

As responsabilidades comuns, porém, diferenciadas buscam estabelecer um princípio de justiça distributiva que impute responsabilidade a cada Estado, na medida de sua contribuição efetiva para os problemas globais e que distribua a carga para a sua solução de forma proporcional à contribuição de cada Estado. E mais: o princípio reconhece as diferentes capacidades de recursos técnicos, financeiros e humanos para o enfrentamento das questões globais, impondo aos Estados mais bem aquinhoados a obrigação jurídica e moral de cooperação, no que se refere à transferência de recursos para que se possa alcançar a almejada solução dos problemas ambientais globais.

\section{OS NOVOS ATORES NO CENÁRIO INTERNACIONAL}

Os sujeitos do DIMA são os entes dotados de personalidade jurídica de Direito Interacional, os quais tradicionalmente, são os Estados nacionais que, pelo menos até os meados do Século XX, eram basicamente os Estados europeus e os do continente americano. Os Estados nacionais, tal como os conhecemos na atualidade, são basicamente construções de origem europeia. Após o processo de descolonização, inúmeros Estados africanos e asiáticos se incorporaram autonomamente à comunidade internacional, reivindicando espeço próprio de atuação. A questão ambiental, surgida na década de 70 do século passado em nível internacional, é, certamente, uma 
das que mais geram atritos entre as antigas potências coloniais e os Estados Unidos com as ex-colônias.

Os Estados nacionais, juntamente com as Organizações Internacionais, ainda que sejam os principais sujeitos de DIMA, vem sendo coadjuvados por inúmeros atores, cujos papéis na construção e implementação de acordos internacionais são cada vez mais relevantes. Algumas questões podem explicar o fenômeno, dentre as quais podem ser destacadas as seguintes: (1) os Estados nacionais, como construção europeia, correspondiam às potências coloniais e, portanto, eram em pequeno número cabendo-lhes ditar a ordem interacional; (2) o processo de descolonização vivido no século XX fez com que novos Estados nacionais fossem acrescidos ao cenário internacional, em sua maioria sem qualquer capacidade militar, econômica ou política relevante; (3) o processo de globalização acarretou que, do ponto de vista concreto, grupos intermediários emergissem na arena internacional com capacidades econômicas, financeiras, políticas e técnicas não raras vezes superiores àquelas da imensa maioria dos Estados. $\mathrm{O}$ consenso de Washington, conjunto de medidas econômicas ${ }^{2}$ a serem adotadas internacionalmente por inspiração do Fundo Monetário Internacional e do Banco Mundial, contribuiu fortemente para a diminuição do papel e do tamanho dos Estados, com reflexos no cenário internacional, acarretando o fortalecimento das instituições intermediárias. Assim, houve uma relativização do papel desempenhado pelos Estados nacionais no contexto internacional, com a diminuição de seus protagonismos.

No campo específico do DIMA, a relativização do papel dos Estados se apresenta de forma dramática, pois grande parte das questões ambientais são de natureza regional ou global, o que determina que os Estados devam "abrir mão" de parte de sua soberania para que, em colaboração com as outras partes dos acordos internacionais, possam enfrentar as poluições transfronteiras ou proteger a diversidade biológica global. Isto acarreta, como se tem percebido na prática internacional, o ingresso de novos atores no cenário jurídico internacional o que, de certa forma, tem gerado perplexidades e incompreensões, as quais se expressam em reações ultranacionalistas contra uma suposta perda de soberania nacional.

2 (1) disciplina fiscal; (2) gastos públicos voltados prioritariamente para saúde e educação; (3) reforma tributária; (4) elevação de juros; (5) valorização da moeda; (6) abertura do comércio internacional; (7) facilitação para os investimentos estrangeiros; (8) desestatização das empresas públicas; (9) desregulamentação da atividade econômica; e, por fim (10) respeito aos direitos de propriedade privada. 


\subsection{Organizações não governamentais}

A participação das Organizações Não Governamentais na sociedade global e nos acordos internacionais é, como foi observado por Vernon I. Tava (2015), parte do processo de globalização e consequência da diminuição do papel dos Estados, tanto na ordem interna, quanto na internacional. Inúmeros poderes foram "devolvidos" à sociedade, acarretando o surgimento da ideia de governança em detrimento da de governo.

A segunda metade do século XX presenciou uma profunda mudança nas relações internacionais e, em especial, no que se refere ao meio ambiente. Os grandes acidentes ambientais internacionais, ${ }^{3} \mathrm{o}$ fim da guerra fria, o chamado neoliberalismo internacional propiciado pela globalização, fizeram com que houvesse um dramático aumento de troca de informações entre os países e as pessoas e grupos, concomitante com aumento de fluxo de capital entre os diversos países, o acelerado desenvolvimento da China e demais países da Ásia, com necessidades crescentes de matérias primas, implicaram em enorme pressão sobre os recursos naturais, propiciando o surgimento do que ficou conhecido como sociedade civil global que é basicamente composta por ONGS, povos indígenas, militantes de base etc. Tais circunstâncias impactaram profundamente a formação do DIMA e, notadamente, a legitimação para participar dos diferentes processos decisórios internacionais no que tange à elaboração de acordos ambientais e seus documentos anexos.

A Governança Global é a soma das diversas formas pelas quais indivíduos e instituições, públicas e privadas, gerenciam seus negócios comuns. É processo contínuo pelo qual interesses diversos ou conflitantes podem ser acomodados e tomadas ações cooperativas. Ela inclui instituições formais e regimes fortalecidos para que os compromissos sejam observados, assim como arranjos informais que pessoas e instituições tenham concordado ou percebidos como de seu interesse, tal como definido pela Comissão de Governança Global em 1995. A Comissão também entendeu que, em nível global, a governança, até então tinha sido entendida como atividade governamental, todavia, desde então, vem sendo encarada como integrada por

3 Como exemplo podem ser citados: a (1) poluição e envenenamento de pescadores por mercúrio na baía de Minamata, Japão nas décadas de 50 e 60 do século XX, os (2) grandes vazamentos de óleo causados pelos petroleiros Torey Canyon e Amoco - Cádiz nas costas europeias na década de 60, a (3) liberação de produtos químicos no ambiente em Seveso, década de 70, a (4) liberação de radiação pela usina nuclear de Three Mile Island, Estados Unidos na década de 70, a (5) poluição química em Love Canal, Estados Unidos, década de 80, a (6) liberação de produtos químicos no ambiente em Bhopal, India com milhares de mortos, na década de 80, a (6) explosão do reator nuclear em Chernobyl, ex-União Soviética, na década de 80, dentre outros tantos. 
organizações não governamentais, cidadãos, movimentos, empresas multinacionais e do mercado de capitais, com a interação da mídia internacional. A principal crítica à governança global é que, certamente, são reconhecidos poderes a entidades que efetivamente não têm a legitimidade do voto popular. Nos últimos anos, o conceito de governança vem sendo desafiada por movimentos nacionalistas que contestam a "perda de soberania" e a crescente burocratização da ordem internacional, como consequência do multilateralismo. Todavia, parece ser evidente que é no multilateralismo que os países em vias de desenvolvimento encontram a melhor forma de expressão de seus anseios comuns perante a comunidade internacional, pois é a única forma de equilibrar o poder diante das superpotências.

\subsubsection{Legitimação das ONGs}

Quando se observa a participação das ONGs no cenário internacional há muita perplexidade. Contudo, há base jurídica para tal participação. A Carta das Nações Unidas (artigo 71) dispõe que o Conselho Econômico e Social (ECOSOC) poderá consultar ONGs dedicadas às questões que estiverem na sua competência, mediante entendimentos com organizações internacionais e, quando for o caso, com organizações nacionais, após consultar os Estados membros da ONU. A Resolução ECOSOC 1996/31 estabelece os requisitos para que uma ONG obtenha status consultivo, após cumpridas determinadas exigências, destacando-se as seguintes: que (1) a ONG tenha entre os seus objetivos a preocupação com os temas de competência do ECOSOC ou de seus órgãos subordinados, que (2) os objetivos e propósitos da ONG devem ser conformes ao espírito, propósitos e princípios da Carta da ONU, que (3) a ONG apoie a ação da ONU e promova o conhecimento de seus princípios e atividades, conforme os seus objetivos e área de atuação. Atualmente existem mais de 5 mil ONGs devidamente registradas no ECOSOC. Há que se observar que as ONGs não são exclusivamente associações civis formadas por militantes de uma causa pública, pois também são admitidas as associações empresariais formadas para a defesa de interesses empresariais legítimos, como é o caso, v.g., do World Business Council for Sustainable Development. É também importante observar que as grandes ONGs internacionais são instituições globais que, em certa medida, agem conforme os seus interesses institucionais e corporativos. De qualquer forma, a atuação das ONGs é relevante, pois muitas vezes, atuam em países com baixo nível de desenvolvimento e, portanto, 
carentes de recursos financeiros, humanos e tecnológicos, compensando tais carências.

As ONGs, certamente, são controversas, pois em muitas ocasiões são acusadas de agirem em benefício de potências estrangeiras em detrimento dos interesses nacionais dos países nos quais atuam. Ainda que sob a designação de $\mathrm{ONG}$ se encontrem associações extremamente díspares entre si, em muitos setores e países, a proteção ambiental depende inteiramente delas. Entidades como WWF, IUCN e tantas outras têm prestado serviços inestimáveis à causa da proteção internacional do meio ambiente, sendo certo que, em muitas regiões do globo terrestre, a atuação delas é indispensável.

Há, em boa parte da crítica à atuação das ONGs, ranço nacionalista e visão equivocada de desenvolvimento econômico, incapazes de compreender a urgência da proteção global do meio ambiente.

\subsection{Indivíduos e Sociedade Civil}

A chamada sociedade civil global, composta por diferentes atores, cada vez mais desempenha papel de relevância no contexto internacional. Sociedade civil é um conceito amplo que engloba inúmeras instituições de natureza diversa, podendo variar desde ONGs (voltadas à defesa do meio ambiente e empresariais) até associações informais, povos indígenas e demais minorias, bem como empresas transnacionais. Aos indivíduos também tem sido reconhecida a possibilidade de atuação internacional. $\mathrm{O}$ princípio 1 da Declaração de Estocolmo expressamente reconhece o direito (fundamental) individual ao desfrute de condições de vida adequadas em um meio ambiente de qualidade tal que lhe permita levar uma vida digna. A Declaração do Rio, em seu Princípio 10 afirma que o melhor meio de gerir as questões ambientais é assegurando o direito de participação, de forma apropriada, a todos os cidadãos interessados. No âmbito interamericano, o Protocolo de São Salvador reconhece, em seu artigo 11 (1), o direito de toda pessoa viver em meio ambiente sadio, dotado com os serviços públicos básicos.

Para o exercício dos direitos de participação foram estabelecidos vários acordos internacionais. Em nível europeu a matéria é tratada na Convenção da Comissão Econômica para a Europa das Nações Unidas (CEE/ONU) sobre Acesso à Informação, Participação do Público no Processo de Tomada de Decisão e Acesso à Justiça em Matéria de Ambiente (Convenção de 
Aarhus) que estabelece os mecanismos para (1) acesso à informação; (2) participação do público em processos decisórios; e (3) acesso à justiça em matéria ambiental. Na América Latina e no Caribe foi celebrado o Acordo Regional sobre o Acesso à informação Participação Pública e Acesso à Justiça em Assuntos Ambientais de 2018 (Escazú, Costa Rica).

As empresas privadas transnacionais também merecem atenção destacada do DIMA, sendo atores cada vez mais relevantes. Conforme anotam Doumbé-Billé et al. (2013) as grandes corporações desempenham um papel dúplice em termos ambientais, seja devido ao seu potencial poluidor, seja pela sua capacidade técnica e financeira para oferecer soluções para os problemas ambientais. O papel das empresas foi expressamente reconhecido pela Declaração de Johanesburgo (item 29), tendo os chefes de Estado concordado com a necessidade de que as corporações do setor privado implementem as suas responsabilidades corporativas, em contexto regulatório transparente e estável.

\subsection{Organizações Internacionais}

Conforme as lições de Dupuy e Viñales (2015) existem quatro tipos de OI, segundo o modelo de sua criação jurídica e suas competências. O primeiro (1) é formado pelas entidades criadas por um tratado constitutivo, com mandato e os seus principais órgãos de gestão definidos, v.g., a (a) Organização Marítima Internacional, a (b) Organização Meteorológica Mundial e (c) a Organização das Nações Unidas para a Alimentação e Agricultura. Há organizações (2) criadas por tratados, todavia, tais tratados não têm como objetivo primário a constituição de uma OI, mas a normatização de um setor da atividade internacional, como por exemplo, a diversidade biológica; em tais casos a instituição é criada para gerir o tratado ou a convenção. Normalmente são criadas conferências das partes ou secretariados. Um terceiro (3) modelo é "subproduto" dos dois anteriores, levando à criação de órgãos subsidiários aos acordos, como é o caso da AGNU ou do Programa das Nações Unidas para o Meio Ambiente (PNUMA). O quarto (4) modelo de Organização Internacional é mais informal, haja vista que não são produtos de tratados ou convenções, direta ou indiretamente. Como exemplo pode ser citado o G $20^{4}$. As Organizações Internacionais desempenham importante papel na articulação da proteção internacional do maio ambiente, pois a formação de consensos no sentido

4 Grupo informal constituído pelos 19 países mais ricos do mundo e a União Europeia.

Veredas do Direito, Belo Horizonte, $\cdot$ v.17 $\cdot$ n.37 $\cdot$ p.263-294 $\cdot$ Janeiro/Abril de 2020 
de que proteger o meio ambiente globalmente demanda coordenação entre os diversos países e blocos econômicos.

\section{OS PRINCÍPIOS JURÍDICO-AMBIENTAIS}

Os princípios gerais de Direito são fontes de Direito. Guido Fernandes da Silva SOARES (2001) identifica cinco fontes de Direito, a saber: O (1) Jus Scriptum dividido em (a) tratados e convenções multilaterais sobre meio ambiente e os (b) atos das organizações intergovernamentais; o (2) costume internacional; os (3) os princípios gerais do Direito; a (4) Doutrina Internacional e a (5) jurisprudência internacional. Para os objetivos deste artigo, apenas os princípios gerais de Direito serão examinados, na exata medida em que contribuam para o estudo dos princípios de DIMA.

O Estatuto da Corte Internacional de Justiça (CIJ), em seu artigo 38 (a) estabelece que a CIJ decidirá os casos com base nas convenções internacionais, quer gerais, quer especiais, que estipulem regras que sejam expressamente reconhecidas pelos Estados litigantes. Por sua vez, as letras (b), (c) e (d) do mesmo artigo, autorizam a CIJ a decidir com base no (b) costume internacional, como prova de uma prática geral aceita como sendo direito e nos (c) princípios gerais de Direito, reconhecidos pelas nações civilizadas e, ainda, (d) ressalvado o disposto no artigo 59 do Estatuto da CIJ, as decisões judiciárias e a doutrina dos juristas mais qualificados das diferentes nações como meio auxiliar para a determinação das regras de Direito (ICJ, [s.d.]).

Todas as fontes acima apresentadas estão sujeitas à influência de fatores externos ao Direito tais como, o (1) conhecimento científico; (2) os grandes acidentes ambientais; (3) o movimento ambientalista; e (4) o contexto econômico. Dentre as diferentes fontes do DIMA, os princípios são das mais controvertidas, em função de sua enorme fluidez e tendência à expansão constante. Agrava o fato que, em matéria de DIMA, o vocábulo princípios é utilizado de forma diferente nos vários acordos internacionais (DOUMBÉ-BILLÉ et al., 2013).

\subsection{Princípios gerais do direito}

De forma sintética, pode-se dizer que os princípios gerais do direito têm por objetivo preencher a lacuna existente entre a regra jurídica e a realidade concreta (GARCIA, 2015). Eles refletem a consolidação de 
práticas e entendimentos jurídicos que utilizados pela comunidade jurídica, desde longa data, espelham os diferentes sistemas de direito existentes. Em última instância, são os fundamentos últimos de uma determinada ordem jurídica que são chamados a intervir para dar solução a um caso concreto nas hipóteses em que a norma positivada não ofereça uma solução evidente. Relembre-se que, entre as fontes de Direito Internacional reconhecidas no Estatuto os princípios gerais do Direito são os "mais vagos" (NASCIMENTO E SILVA, 2002).

Todavia, após o fim do ciclo colonial e o reconhecimento de direitos locais que estavam subjugados à ordem colonial, cabe a pergunta: De que Direito falamos e de quais princípios? Fato é que a ordem jurídica contemporânea, internacional ou interna, é caleidoscópica (HESPANHA, 2009).

A concepção de Direito que serve de base para a discussão princípios gerais é fundamentalmente a ocidental e, no DIP, aquela que resultou das estruturas coloniais e do período imediatamente após a $2^{\text {a }}$ Guerra Mundial. Tal situação é claramente expressa no artigo 38 (1) (c ) do Estatuto da CIJ ao reconhecer como princípios gerais de Direito somente os das "nações civilizadas". A norma, à toda evidência, parte do pressuposto de que os povos submetidos ao regime colonial não possuíam estruturas de controle social e organização da vida em sociedade que pudessem ser classificadas como Direito (KELSEN, 1979), muito menos "Direito civilizado". Neste ponto vale relembrar a observação de Soares (2001) no sentido de que os redatores do Estatuto da Corte Permanente de Justiça Internacional (CPJI), antecessora da CIJ, no entre guerras, "se acreditavam de tal maneira representantes da civilização" que adjetivaram os princípios gerais do Direito. Acrescente-se, com Kiss (1989), que o conceito de nação civilizada é contestado e controverso.

O Direito ocidental, o "Direito das nações civilizadas" não é mais soberano como fora na época da colonização, ou pretendeu ser. A atualidade tem reconhecido, cada vez mais, os Direitos autóctones, como, v.g., ocorreu nos chamados casos Mabo (1 e 2), julgados pela Suprema Corte Australiana, envolvendo terras do povo Merian, grupo aborígene que postulava direitos sobre as ilhas Murray, consideradas terra nullius (HCOURT, 2019). Em Mabo (1) a Suprema Corte australiana declarou que as terras australianas, antes da chegada dos colonos ingleses, não eram terrae nullius, sendo o povo Merian o seu legítimo proprietário. Em Mabo (2) a Corte adotou a doutrina do título nativo de propriedade, reconhecendo que os aborígenes foram legitimamente expropriados de suas terras tradicionais, admitindo 
a existência de uma ordem jurídica plural (HESPANHA, 2013). Em nível internacional, a Convenção 169 da Organização Internacional do Trabalho sobre Povos Indígenas e Tribais, reconhece os povos "cujas condições sociais, culturais e econômicas os distingam de outros setores da coletividade nacional, e que estejam regidos, total ou parcialmente, por seus próprios costumes ou tradições"'(artigo $1^{\circ}(1)(a)$.

O modelo exclusivo do Direito ocidental, não se sustenta mais, pois a antropologia nos mostra que qualquer sociedade, por mais "bárbara" e "primitiva" que seja traz em si um sentido de ordem, sem o qual "não há humanidade possível" (ASSIER-ANDRIEU, 2000, p. 98), logo de Direito. A multiplicidade dos Direitos é hoje um fato reconhecido e, portanto, a definição de um conjunto de princípios gerais válidos para todo e qualquer sistema jurídico é tarefa cada vez mais difícil, senão impossível. Decorre daí que o simples reconhecimento dos princípios gerais de Direito "das nações civilizadas" é anacronismo incompatível com a realidade moderna.

\subsubsection{Principios no DIMA}

Como nos adverte Alexandre KISS, no que diz respeito ao DIMA, os textos legislativos "pululam" (1989), sendo necessário para que se identifiquem os seus princípios que haja uma consolidação de tais documentos, com pesquisa exaustiva com vistas à identificação das ideias que lhes são subjacentes.

O termo princípio se disseminou de forma espantosa no Direito Internacional do Meio Ambientet, sendo utilizado indistintamente em documentos com variável força jurídica. Para os fins deste artigo, considera-se como primeiro grande documento internacional a tratar de princípios de DIMA, a Declaração de Estocolmo de 1972 que contém 26 princípios. Por sua vez, a Declaração do Rio de 1992 contém 27, conforme anotado por Handl (2012). Parece evidente que tal proliferação de princípios, ainda que proclamados por meio de documentos não obrigatórios, indica que se cuida mais de afirmação de diretrizes políticas do que de normas jurídicas. Vale ressaltar que o Preâmbulo da versão inglesa da Declaração de Estocolmo fala em "common principles to inspire and guide" (princípios comuns para inspirar e guiar) os povos, o que indica sua inafastável natureza orientadora e não mais do que isto. A Declaração do Rio é ambígua, pois apesar de proclamar 27 princípios, estabelece que os princípios 15 (precaução) e 16 (poluidor pagador) são na verdade, conforme a redação em língua inglesa, 
"approaches" "que deverão ser levados em consideração pelas autoridades nacionais. Parece claro que as grandes conferências ambientais, cientes de suas limitações políticas e jurídicas, não se utilizaram do vocábulo princípio, como equivalente a "princípios gerais de direito" tal como especificado pelo artigo 38, (1) (c) do Estatuto da CIJ. Aliás, tal cuidado fica claro na redação dos princípios 15 e 16 da Declaração do Rio, com a inclusão do vocábulo approach, na versão original, o que ocorre igualmente na versão francesa que se utiliza do termo "mesures" (medidas) (ANTUNES, 2016).

Os acordos ambientais também refletem a ambiguidade já mencionada. A Convenção de Estocolmo sobre Poluentes Orgânicos Persistentes utiliza a palavra approach (artigo $1^{\circ}$ ), ainda que se refira ao Princípio 15 da Declaração do Rio ; por sua vez a CDB, ao seu utilizar do vocábulo princípio (artigo $3^{\circ}$ ), o faz de forma tradicional, indicando princípios plenamente estabelecidos no DIP , tais como: (1) soberania, “ [o]s Estados, em conformidade com a Carta das Nações Unidas e com os princípios de Direito Internacional, têm o direito soberano de explorar seus próprios recursos segundo suas políticas ambientais", (2) responsabilidade internacional, "responsabilidade de assegurar que atividades sob sua jurisdição ou controle não causem dano ao meio ambiente de outros Estados ou de áreas além dos limites da jurisdição nacional."

Logo, princípio em DIMA, é um vocábulo polissêmico cujo valor jurídico é correspondente ao do documento internacional no qual ele esteja inserido. Entretanto, é importante ressaltar que não há consenso na doutrina jurídica internacional sobre (1) o número de princípios de Direito Internacional do Meio Ambiente; e (2) sobre quais são os princípios do DIMA. Entretanto, as dificuldades políticas que usualmente estão presentes na elaboração de acordos internacionais recomendam a adoção de fórmulas abertas. Quanto mais difícil a negociação, mais aberto será o documento que dela emergirá.

É possível, portanto, observar que, nos acordos ambientais com força obrigatória (tratados e convenções) a utilização do termo princípio tende a ser feita de forma conservadora e tradicional, limitando-se aos conceitos consensuais. Por outro lado, quando se trata de declarações, texto político e sem força jurídica, a expansão dos princípios parece ser a regra.

Assim, nos acordos cogentes são reconhecidos princípios tais como: (1) princípio da soberania sobre os recursos naturais e de não causar danos

5 As versões em língua portuguesa adotadas pelo Brasil, inexplicavelmente traduzem approach por princípio. 
a terceiros estados, bens ou pessoas; (2) princípio da cooperação; (3) princípio da responsabilidade comum, porém diferenciada; (4) princípio do desenvolvimento sustentável Por sua vez, as declarações políticas acolhem princípios mais amplos e controversos tais como (1) princípio da precaução; e (2) princípio do poluidor pagador. Em última instância, a existência de uma relação de princípios no bojo dos acordos internacionais, conforme definido pela Corte Permanente de Justiça no célebre Caso Lótus, depende da vontade livremente manifestada pelos Estados. Nesta altura, é conveniente relembrar a ácida crítica formulada por Martine Rèmond-Gouilloud $(1989$, p. 37) ao falar sobre uma "inflação de falsas fontes" e de "grandes fórmulas" que, embora bem construídas, não têm qualquer força obrigatória. Assim, é importante evitar uma metástase principiológica que terá muita pouca utilidade, senão nenhuma, para uma efetiva aplicação do Direito Internacional do Meio Ambiente.

\section{CONCLUSÕES}

O DIMA é um novo ramo do DIP que tem se afirmado nas últimas décadas como um dos mais inovadores instrumentos de proteção do meio ambiente em nível global. Ele vem se constituindo ao longo dos últimos 50 anos a partir de demandas concretas que têm origem no fenômeno da poluição transfronteira, cujo primeiro reconhecimento é anterior à segunda metade do Século XX, tendo resultado da disputa entre dois países desenvolvidos. A responsabilidade internacional dos Estados por danos causados a terceiros, em função de poluição advinda de seu território, é hoje amplamente aceita. Todavia, a disparidade entre os diferentes membros da comunidade internacional fizeram com que o conceito de responsabilidade internacional fosse mitigado no sentido de se entender que há uma responsabilidade de todos os Estados com a proteção ambiental que, entretanto, deve ser proporcional à poluição causada por cada Estado individualmente considerado e, igualmente, às suas diferentes capacidades de enfrentá-la. Aqui não se deve esquecer a questão relativa à soberania dos Estados sobre os seus recursos naturais, reconhecida em acordos com força obrigatória.

A experiência internacional comprovou a impossibilidade prática de que o tema ambiental seja tratado de forma unitária, gerando a setorialização dos acordos, seja por regiões geográficas, seja por área temática. Todavia, a multiplicidade de acordos gera dificuldades concretas para sua implementação, diante da ausência de harmonização entre eles, além dos 
fatores de ordem política, social e econômica. A construção de organismos específicos para a gestão e implementação dos acordos é outro ponto saliente do DIMA. As mudanças estruturais nas economias globais sob a égide do consenso de Washington, com o enfraquecimento das entidades estatais, trouxeram novos atores para o cenário internacional (ONGs, povos indígenas etc.) que, em matéria ambiental, desempenham papel relevante, assim como as corporações multinacionais.

O DIMA é direito principiológico, isto é, tende a recorrer a princípios abertos como forma de acomodar diferentes visões sobre o meio ambiente. Os princípios, todavia, serão cogentes ou não, conforme a natureza do documento internacional nos quais estejam insertos. Não há, portanto, que se falar em princípios com igual valor jurídico.

As diversas particularidades do DIMA, certamente, elevam-no à dignidade de um ramo autônomo do DIP que ganha importância no mundo moderno. As novas concepções relativas ao desenvolvimento, à participação da sociedade e à soberania são relevantes, pois buscam a acomodação entre Estados com grandes diferenças entre si que, efetivamente, precisam ser minimizadas para que possa haver paz entre as nações e que, por meio da cooperação, os graves problemas ambientais e sociais possam ser adequadamente manejados nos fora multilaterais.

O DIMA, entretanto, é um Direito ainda imaturo, pois as suas estruturas ainda carecem das necessárias consolidação e estabilidade que permitam ao Direito oferecer segurança às partes. Por fim, cuida-se de um Direito que é uma esperança de solução pacífica dos graves problemas ambientais que assolam o planeta, assim como é uma esperança de entendimento igualitário entre as nações, com vista a solução de seus problemas comuns.

\section{REFERÊNCIAS}

AIATSIS - AUSTRALIAN INSTITUTE OF ABORIGINAL AND TORRES STRAIT ISLANDER STUDIES. Mabo case. Acton: AIATSIS, 2019. Disponível em: https://aiatsis.gov.au/explore/articles/mabo-case. Acesso em: 22 set. 2019.

ACIDENTE NUCLEAR em Three Mile Island, Estados Unidos. Energia Nuclear, 2 maio 2019. Disponível em: https://pt.energia-nuclear.net/acidentes-nucleares/three-mile-island.html. Acesso em: 23 set. 2019.

ANTUNES, P. B. Dano ambiental: uma abordagem conceitual. 2. ed. São Paulo: Atlas, 2015. 
ANTUNES, P. B. Precautionary Principle on Brazilian Environmental Law. Veredas do Direito, Belo Horizonte, v. 13, n. 27, p. 63-88, set./dez. 2016. Disponível em: http:/www.domhelder.edu. br/revista/index.php/veredas/article/view/877. Acesso em: 7 jul. 2019.

ASSIER-ANDRIEU, L. O Direito nas Sociedades Humanas. São Paulo: Martins Fontes. 2000.

BRASIL. Câmara dos Deputados. Decreto Legislativo n. 144, de 2002. Aprova o texto do Protocolo de Quioto à Convenção-Quadro das Nações Unidas sobre Mudança do Clima, aberto a assinaturas na cidade de Quioto, Japão, em 14 de dezembro de 1997, por ocasião da Terceira Conferência das Partes da Convenção-Quadro das Nações Unidas sobre Mudança do Clima. Brasília, DF: Câmara dos Deputados, 2002. Disponível em: https:// www2.camara.leg.br/legin/fed/decleg/2002/decretolegislativo-144-20-junho-2002-458772-protocolo-1-pl.html. Acesso em: 24 mar. 2020.

BRASIL. Ministério do Meio Ambiente. Convenção de Viena e Protocolo de Montreal. Disponível em: http://www.mma.gov.br/clima/protecao-da-camada-de-ozonio/convencao-de-viena-e-protocolo-de-montreal. Acesso em: 9 jul. 2019.

BRASIL. Ministério das Relações Exteriores. Atos Internacionais. Disponível em: http://www.itamaraty.gov.br/pt-BR/663-atos-internacionais. Acesso em: 26 mar. 2020.

CALVO, T. L. Derecho Internacional del Medio Ambiente. Barcelona: Atelier, 2005.

CARSON, R. Primavera silenciosa. São Paulo: Gaia, 2010.

CMED - COMISSÃO MUNDIAL SOBRE MEIO AMBIENTE E DESENVOLVIMENTO. Nosso futuro comum. Rio de Janeiro: Fundação Getúlio Vargas, 1988.

CORNWALL, A.; EADE, D. (Eds.). Deconstructing development discourse-buzzwords and fuzzwords. Oxford: Practical Action, 2010.

DOUMBÉ-BILLÉ, S. et al. Droit International de L`Environnement. Bruxelles: Larcier, 2013.

DUPUY, P.-M.; VIÑALES, J. E. Introduction au Droit International de L'environnement. Bruxelles: Bruylant. 2015. 
EARTH CHARTER INITIATIVE. Disponível em: http:/earthcharter. org/\#. Acesso em: 26 set. 2019.

EBLEN, R. A.; EBLEN, W. R. (Eds.). The Encyclopedia of the Environment - The René Dubos Center for Human Environment. Boston; New York: Houghton Mifflin Company, 1994.

ESCALA INES - Escala Internacional de Eventos Nucleares. Energia Nuclear, 2019. Disponível em: https://pt.energia-nuclear.net/acidentes-nucleares/escala-ines.html. Acesso em: 23 set. 2019.

FUNDO AMAZÔNIA. Disponível em: http://www.fundoamazonia.gov. br/pt/home/. Acesso em: 24 set. 2019.

GARCIA, M. G. O lugar do Direito na proteção do ambiente. Coimbra: Almedina, 2015.

HANDL, G. Declaration of the United Nations Conference on the HUMAN ENVIRONMENT (Stockholm Declaration), 1972 and the Rio Declaration on Environment and Development, 1992, (2012). Disponível em: http:// legal.un.org/avl/pdf/ha/dunche/dunche_e.pdf. Acesso em: 24 set. 2019.

HANNIGAN, J. Environmental sociology. 3. ed. London; New York: Routledge, 2014.

HCOURT - HIGH COURT OF AUSTRALIA. Disponível em: http:// www.hcourt.gov.au/. Acesso em: 6 set. 2019.

HESPANHA, A. M. O caleidoscópio do Direito: o Direito e a Justiça nos dias e no mundo de hoje. 2. ed. Coimbra: Almedina, 2009.

HESPANHA, A. M. Pluralismo jurídico e Direito democrático. São Paulo: Annablume. 2013.

ICJ - INTERNATIONAL COURT OF JUSTICE. Statute of the International Court of Justice. Disponível em: https://www.icj-cij.org/en/statute. The Hague: ICJ, [s.d.]. Acesso em: 22 set. 2019.

ICJ - INTERNATIONAL COURT OF JUSTICE. Affaire du lotus. Recueil des Arreêts, Série A, n. 70, 7 set. 1927. Disponível em: https://www.icj-cij. org/files/permanent-court-of-international-justice/serie_A/A_10/30_Lotus_Arret.pdf. Acesso em: 23 set. 2019.

ICJ - INTERNATIONAL COURT OF JUSTICE. Gabčíkovo-Nagymaros Project (Hungary/Slovakia). Disponível em: https://www.icj-cij.org/en/ case/92. The Hague: ICJ, 1992. Acesso em: 22 set. 2019. 
KELSEN, H. Teoria pura do Direito. 4. ed. Coimbra: Armênio Amado, 1979.

KISS, A. Droit International de L 'Environnement. Paris: Pedone, 1989.

LAVIELLE, J.-M.; DELZANGLES, H.; LE BRIS, C. Droit International de l'Environnement. 4. ed. Paris: Ellipses, 2018.

MALJEAN-DUBOIS, S. Quel Droit pour L'environnement? Paris: Hachette, 2008.

McCORMICK, J. Rumo ao paraíso: a história do movimento ambientalista. Rio de Janeiro: Relume Dumará. 1992.

MEADOWS, D. H. M. et al. Limites do crescimento. São Paulo: Perspectiva, 1977.

MORAND-DEVILLER, J. Le Droit de L'Environnement. 10. ed. Paris: PUF, 2010.

NASCIMENTO E SILVA, G. E. Direito Ambiental Internacional. 2. ed. Rio de Janeiro: Thex, 2002.

ONU - ORGANIZAÇÃO DAS NAÇÕES UNIDAS. Declaração do Rio sobre Meio Ambiente e Desenvolvimento. Rio de Janeiro: ONU, 1992. Disponível em: https://cetesb.sp.gov.br/proclima/wp-content/uploads/sites/36/2013/12/declaracao_rio_ma.pdf. Acesso em: 25 set. 2019.

ONU - ORGANIZAÇÃO DAS NÇÕES UNIDAS. Declaração de Estocolmo sobre o ambiente humano. Estocolmo: ONU, 1972. Disponível em: http://www.direitoshumanos.usp.br/index.php/meio-ambiente/declaracao-de-estocolmo-sobre-o-ambiente-humano.html. Acesso em: 25 set. 2019.

PEPPER, D. Ambientalismo moderno. Lisboa: Instituto Piaget, 2000.

REI, F. C. F. International Environmental Law and global environmental governance: southern influences. Veredas do Direito, Belo Horizonte, v. 15, n. 32, p. 143-165, maio/ago. 2018. Disponível em: http://www.domhelder.edu.br/revista/index.php/veredas/article/view/1257. Acesso em: 29 jun. 2019.

RÈMOND-GOUILloud, M. Du Droit de Détruire: essai sur le Droit de L`Environnement. Paris: PUF. 1989

REZEK, F. Direito Internacional Público: curso elementar. 9. ed. São Paulo: Saraiva, 2002. 
ROMI, R. Droit de LÈnvironnement. 7. ed. Paris: Montchrestien, 2010.

SAKAGUCHI, K. Para resolver o problema do metil-mercúrio na Amazônia. Japan International Cooperation Agency, 12 ago. 2010. Disponível em: https://www.jica.go.jp/brazil/portuguese/office/articles/100812.html. Acesso em: 20 set. 2019.

SANDS, P.; PEEL, J. Principles of International Law. 3. ed. Cambridge: Cambridge University Press, 2017.

SOARES, G. F. S. Direito Internacional do Meio Ambiente: emergência, obrigações e responsabilidades. São Paulo: Atlas, 2001.

TAVA, V. I. The role of non-governmental organizsations, peoples and courts in implementing international environmental laws. In: ALAM, S. et al. (Eds.). Routledge handbook of International Environmental Law. London; New York: Routledge, 2015. P. 123-136.

UNITED NATIONS. Introduction to ECOSOC Consultative Status. Disponível em: http://csonet.org/?menu=30. Acesso em: 26 set. 2019.

UNITED NATIONS. Permanent Sovereignty over Natural Resources General Assembly Resolution 1803 (XVII). New York, 14 dec. 1962. Disponível em: http://legal.un.org/avl/ha/ga_1803/ga_1803.html. Acesso em: 26 set. 2019.

UNITED NATIONS. General Assembly - Quick Links. Disponível em: https://research.un.org/en/docs/ga/quick/regular/44. Acesso em: 25 set. 2019.

UNITED NATIONS. United Nations Environment Programme. Global Environment Outlook 6, 4 mar. 2019a. Disponível em: https://www.unenvironment.org/resources/global-environment-outlook-6. Acesso em: 24 set. 2019.

UNITED NATIONS. LDCs at a Glance. Disponível em: https://www. un.org/development/desa/dpad/least-developed-country-category/ldcs-at-a-glance.html. Acesso em: 26 set. 2019 b.

UNITED NATIONS. United Nations Environment Programme. Register of international treaties and other agreements in the field of the environment. Nairobi: UNEP, 2005. Disponível em: https://www.unenvironment. org/resources/report/register-international-treaties-and-other-agreements-field-environment. Acesso em: 25 set. 2019. 
UNITED NATIONS. Trail smelter case (United States, Canada): 16 april 1938 and march 1941. Reports of International Arbitral Awards, v. III, p. 1905-1982, 2006. Disponível em: https:/www.ecolex.org/details/court-decision/trail-smelter-case-united-states-v-canada-b86fd680-d04e-4245-a1c2-44a1191170c0/. Acesso em: 22 set. 2019.

VARELLA M. D. O surgimento e a evolução do Direito Internacional do Meio Ambiente: da proteção da natureza ao desenvolvimento sustentável. In: VARELLA, M. D.; BARROS-PLAUTAU, A. F. (Orgs.). Proteção internacional do meio ambiente. Brasília: Unitar/UniCEUB/ UnB, 2009. p. 6-25.

Artigo recebido em: 11/07/2019.

Artigo aceito em: 11/02/2020.

\section{Como citar este artigo (ABNT):}

ANTUNES, P. B. Direito Internacional do Meio Ambiente: particularidades. Veredas do Direito, Belo Horizonte, v. 17, n. 37, p. 263-294, jan.-abr. 2020. Disponível em: http://revista.domhelder.edu.br/index.php/veredas/ article/view/1591. Acesso em: dia mês. ano. 